\title{
From high strength and high performance concrete to high performance RC bending elements
}

\author{
I. Iskhakov \& Y. Ribakov \\ Department of Civil Engineering, Ariel University Center of Samaria, \\ Ariel, 44837, Israel
}

\begin{abstract}
Many achievements in recent studies in the field of RC structures are related to high performance phenomenon. This phenomenon can have structural, technological or economical aspects, but it is not always emphasized. Moreover, each structure's improvement cannot be defined as high performance - it can be just upgrading some of its definite properties. Hence, a problem of a strong definition of high performance structural element arises. This paper deals with definition, related to the structural aspect only taking into account that a concept of high performance RC structure is mainly related to bending elements. Considering concrete behavior in these elements, it is important to achieve high performance properties separately for tensile and compressed zones of a bending section. For this reason it is logical to use different concrete classes, i.e. high and normal strength concretes in the compressed and tensile zones, respectively. It is necessary to provide suitable section ductility in the compressed zone and necessary cracking resistance in the tensile zone. A high strength concrete with elastic-plastic properties should be used in the bending element section compressed zone in order to withstand both static and dynamic loads. With this aim fibered concrete is used and the fiber quantity should be calculated according to the required ductility. Using pre-stressed reinforcement in the tensile section zone allows for improvement of the cracking resistance and reduces the bending elements' deflections. Thus, a two-layer RC beam represents an effective bending element having fibered high strength concrete in its section compressed zone and pre-stressed normal strength concrete in the tensile zone. Such a beam can be defined as a high performance bending element, because, on one hand, the concrete compression properties are maximally used for a given ductility level, and, on the other hand, the section's design stiffness requirements are provided by pre-stressing the tensile zone.

Keywords: high performance bending element, high strength concrete, high performance concrete, steel fibers, ductility, pre-stressed elements.
\end{abstract}




\section{Introduction}

Many researchers have investigated experimentally and theoretically behavior structures made of high strength concrete (HSC) [1, 3-6 etc.]. In most cases the HSC class was selected based on engineering experience and varied from 60 $\mathrm{MPa}$ to $240 \mathrm{MPa}$. At the same time, it is reasonable to give a rigorous definition of HSC based on analysis of the available experimental data [2]. This definition is given by the authors in [7]. According to this definition, HSC is defined as the lowest concrete strength, satisfying the following requirements: absence of a download branch in the parabolic diagram of the concrete; minimum exponent of the $\sigma_{c}-\varepsilon_{c}$ function; and minimum ductility parameter of the concrete under compression.

HSC elements behave elastically hence there is no redistribution of bending moments between their sections, and the ductility of such elements is very low. According to experimental results, fibers may be used to increase the ductility of HSC beams [1]. Using steel fibers in the tensile zone adds to the beam's costs; at the same time, the resistance of concrete under tension due to bending is not taken into account. For both these reasons the authors have proposed to include fibers only in the compression zone, where HSC is used [7]. Additionally, in order to improve the element's performance in the tensile zone, the reinforcement in this zone is pre-stressed [8]. This is one of design solutions in which concrete in the bending element's section becomes high performance (HPC).

High performance bending elements should be first of all made of HPC. However, there is no need to use expensive HPC in both compressed and tensile zones of the element's section. It is known that concrete of the tensile zone is not taken into account in the section's bearing capacity in bending. According to Eurocode 2 [2], the tensile zone does not contribute to the section's shear bearing capacity either. Hence, the authors' idea of using two-layer beams, including HPC in the section's compressed zone and normal strength concrete (NSC) in the tensile zone [7], allows effective performance of bending elements and decreases their cost.

This paper reviews existing methods for design of two-layer $\mathrm{RC}$ bending elements, and it is aimed at giving a definition of high performance bending elements (HPBE). An original contribution for the first time conditions, allowing achieving HPBE, is determined.

\section{Two-layer bending element from NSC and fibered HSC}

Two-layer bending elements consisting of steel fibered HSC in the compression zone and NSC in the tensile zone (Figure 1) were studied by the authors [7]. In such elements the bending moment should have the same sign along the entire length of the beam. Additionally, the depth of the compression zone in bending must be constant and equal to its maximal value. 

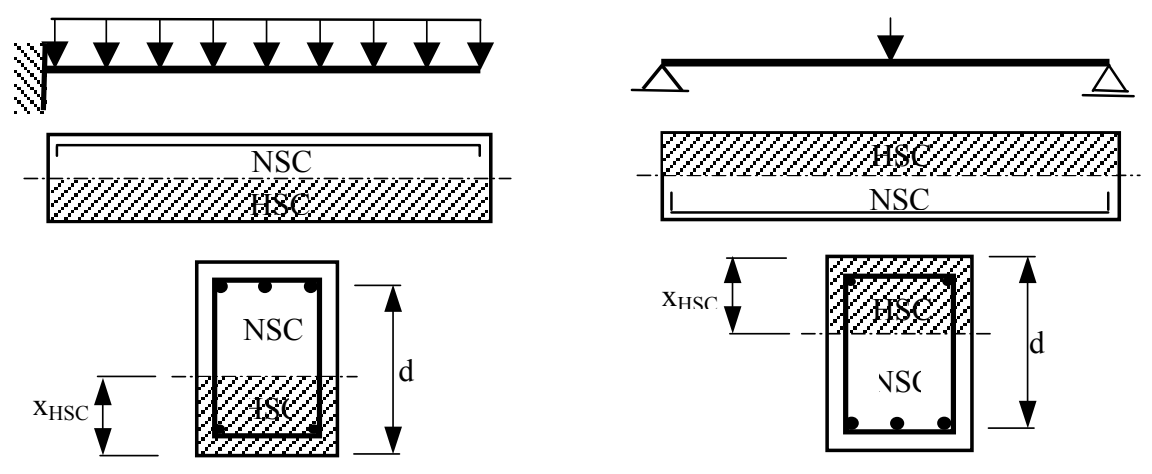

Figure 1: $\quad$ Two layer bending elements.

The shear capacity in such elements can be obtained as follows:

$$
\mathrm{V}_{\mathrm{R} d 1}=\mathrm{V}_{\mathrm{R} d 1}^{\mathrm{HSC}}+\mathrm{V}_{\mathrm{R} d 1}{ }^{\mathrm{NSC}} ; \quad \mathrm{V}_{\mathrm{R} d 2}=\mathrm{V}_{\mathrm{R} d 2}{ }^{\mathrm{HSC}}+\mathrm{V}_{\mathrm{R} d 2}{ }^{\mathrm{NSC}}
$$

where $\mathrm{V}_{\mathrm{R} d 1}$ and $\mathrm{V}_{\mathrm{R} d 2}$ are the concrete section shear capacity without and with links, respectively [9]. An additional requirement for the HSC shear stresses on the border of two concretes is $\tau^{H S C} \leq f_{R d}{ }^{N S C}$, where $f_{R d}{ }^{N S C}$ is the concrete shear strength in a diagonal direction [9]. Adding fibers to the HSC increases the shear strength of a section and prevents its shear failure [1].

Another problem, encountered in the design of two-layer RC sections, concerns the depth of the compression zone, $x_{\mathrm{HSC}}$. The main difficulty is that the depth under bending and that under shear are different. The former is calculated, whereas the latter is a constant value specified by design codes [2,9]. The depth chosen for the HSC layer must satisfy both these requirements. According to the current code provisions [2], the depth under shear equals $0.2 d$, and under bending it is between $0.1 d$ and $0.4 d$ (see Figure 1). In the case of a two-layer beam the minimal value of the concrete compressed zone depth under bending should be $0.2 d$. So the range of $x_{\mathrm{HSC}}$ for bending narrows:

$$
x_{\mathrm{HSC}}=(0.2 \ldots 0.4) d
$$

Increasing the lower limit of the concrete compressed zone depth, $x_{\mathrm{HSC}}$, may yield an increase of section reinforcing. It means that the two-layer RC beams are effective for cases when the calculated depth of the compressed zone corresponds to Eq. (2), i.e. when the RC section carries rather large bending moments. This assumption should be one of the basic provisions for the implementation of such two-layer HSC beams.

\section{Definition of HSC}

The authors gave a rigorous definition of HSC based on analysis of strength and deformation characteristics of different concrete classes [2]. The data given in Table 3.1 of the Eurocode 2 [2] was processed. Results of the analysis are presented in Figure 2. The symbols in the figure correspond to those used in the Euro Code 2 [2]. 


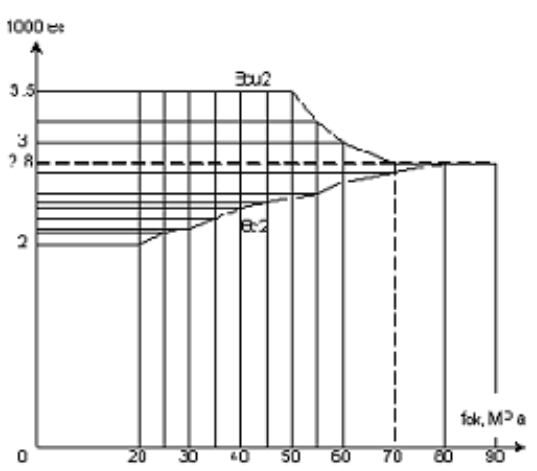

(a)

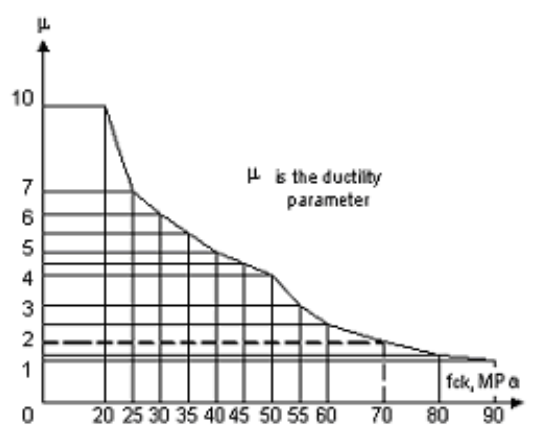

(c)

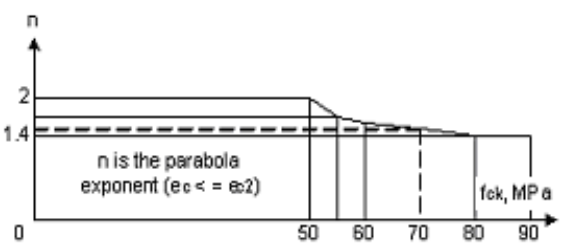

(b)

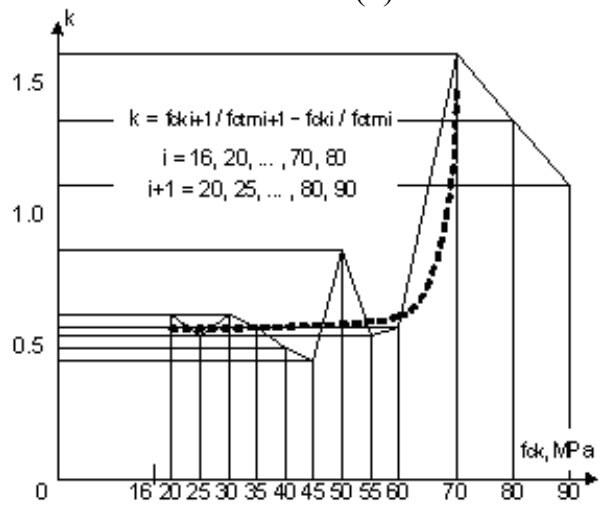

(d)

Figure 2: $\quad$ Influence of $f_{\mathrm{ck}}$ on: deformations (a), parabola exponent (b), ductility parameter (c), $k$ (d) (following [7]).

In our rigorous definition, HSC is defined by the following four conditions:

- there is no download branch in the " $\sigma_{c}-\varepsilon_{c}$ " diagram of the concrete (i.e. $\varepsilon_{c u l}$ $\left.=\varepsilon_{c l}\right)$;

- $\quad$ the $\sigma_{c}-\varepsilon_{c}$ parabolic function has a minimum exponent (i.e. $n=1.4$ );

- the ductility parameter $\mu$ (according to the $\sigma_{\mathrm{c}}-\varepsilon_{\mathrm{c}}$ diagram) is rather small and the failure of the specimen is brittle $(\mu \approx 1)$;

- $\quad$ the concrete tensile strength practically does not increase.

\section{Design of two-layer pre-stressed bending elements}

Design methods for two-layer bending elements with steel fibered HSC in the compressed zone and pre-stressed NSC in the tensile zone (SFHSC/NSC) were developed by the authors [10]. The design of such beams forms a new class of problems in RC structures:

- obtaining the HSC class for a pre-stressed beam according to a given NSC one;

- calculation of steel fiber ratio as a function of the required pre-stressed section's ductility; 
- calculation of minimum and maximum steel fiber (SF) volume ratios.

Usually selection of the SF volume ratio was made based on engineering experience, technological requirements, etc. Most experimental investigations have been curried out for SF volume ratios that were selected in this way and varied from 0.5 to $2.5 \%[1,11,12]$. The lower limit of this ratio is recommended in [13]. Based on experimental investigations that have been performed by other researchers $[1,11,12,14-17]$, the authors have developed a strong theoretical background for the design of HPBE.

\section{Calculation of lower HSC class limit for two-layer pre-stressed beams}

In the tensile zone of bending $\mathrm{RC}$ elements, plastic deformations appear in the concrete matrix before cracking, as in any tensile material. A corresponding idealized "stress-strain" diagram for tensile concrete is shown in Fig. 3(a).

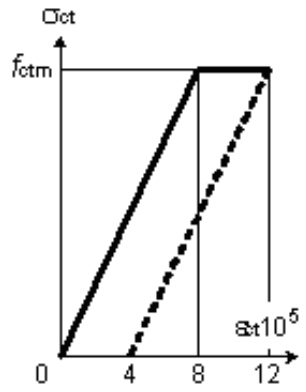

(a)

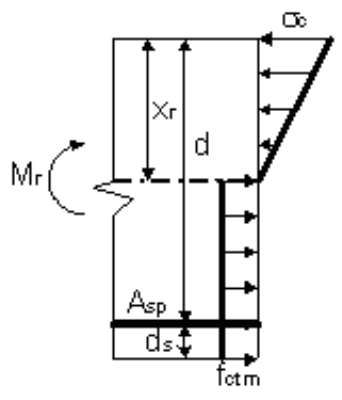

(b)

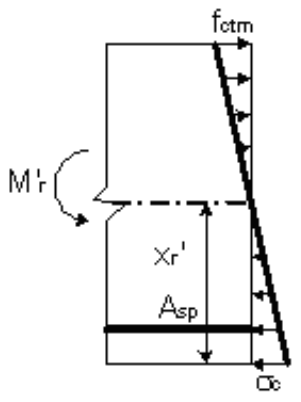

(c)

Figure 3: Idealized " $\sigma-\varepsilon$ " diagram of tensile concrete: (a) crack limit state; (b) under external moment; (c) due to pre-stressing forces.

In this figure the symbols are given as in [2] and

$\mathrm{M}_{\mathrm{r}}$ and $\mathrm{M}_{\mathrm{r}}$ - section bottom (pre-stressed) and top zones cracking bending moments;

$x_{\mathrm{r}}$ and $x_{\mathrm{r}}{ }^{\prime}-$ corresponding neutral axis depth of the tensile and compressed zones.

The section bottom zone cracking moment (see Fig. 3(b)) is

$$
\mathrm{M}_{\mathrm{r}}=0.167 \mathrm{~b} h^{2} f_{\mathrm{ctm}}\left[\left(1-\omega_{\mathrm{r}}\right)\left(\omega_{\mathrm{r}}+3\right)+2 n \rho\left(2.73-\omega_{\mathrm{r}}\right)\right]
$$

where $\omega_{\mathrm{r}}=x_{\mathrm{r}} / h, \quad n=\mathrm{E}_{\mathrm{s}} / \mathrm{E}_{\mathrm{c}} \quad$ and $\rho=\mathrm{A}_{\mathrm{s}} /(b d)$.

For example, for a bending element rectangular section with $b=30 \mathrm{~cm}, h=$ $60 \mathrm{~cm}, \quad d_{\mathrm{s}}=0.1 d, d=0.91 h, n=9, \rho=1 \%, f_{\mathrm{ctm}}=1.77 \mathrm{MPa}$, the section lower zone bending moment at cracking $\mathrm{M}_{\mathrm{r}}=62.33 \mathrm{kN} \mathrm{m}$. For the section upper zone (without reinforcement) the bending moment at cracking for a given $\omega_{\mathrm{r}}{ }^{\prime}=x_{\mathrm{r}}{ }^{\prime} / h=$ 0.5 is 


$$
\mathrm{M}_{\mathrm{r}}^{\prime}=0.167 \mathrm{~b} h^{2} f_{\mathrm{ctm}}(1+4 n \rho)=43.2 \mathrm{kN} \mathrm{m} ; \mathrm{M}_{\mathrm{r}}=1.443 \mathrm{M}_{\mathrm{r}}{ }^{\prime}
$$

Experimentally the relation between $\mathrm{M}_{\mathrm{r}}^{\prime}$ and $\mathrm{M}_{\mathrm{r}}$ was investigated by many researches. As can be followed from [19], for three pre-stressed beams that were tested, the relation varied from 1.252 to 1.716 (the average value was 1.536), which is in good agreement with the theoretically obtained result (see Eq. (4)). If a pre-stressed element's section has two-layers, the minimum concrete tensile strength for the upper HSC layer is

$$
\min f_{\mathrm{ctm}}{ }^{\mathrm{HSC}}=\frac{M_{r}}{M_{r}^{\prime}} f_{\mathrm{ctm}}{ }^{\mathrm{NSC}}
$$

In this case cracks will not appear in that layer under negative moment due to pre-stressing forces. This condition may be used to calculate the HSC class according to a given bottom layer NSC class. Eq. (5) also defines a lower value of the HSC class that may be used in two-layer beams for a given NSC class. The real HSC class should be selected based on the design value of the compressed concrete strength.

\section{Ductility of a pre-stressed concrete section}

The ductility parameter for a two-layer section, consisting of compressed HSC and tensile pre-stressed NSC zones, is very small and its value is near to 1.0, i.e. a bending element section is brittle. It limits the application possibilities of such structures under seismic and other dynamic loadings. Therefore it is reasonable to use SF in order to get HPC in the section's compressed zone. It should also be mentioned that because the concrete action in tension is neglected, there is no need to use HPC in the section's tensile zone and no fibers are added to the NSC.

The minimum SF volume ratio for different HSC classes was found based on [13]. It shows that the ratios of $0.5 \ldots 2.5 \%$, used by many researchers in experimental works, are close only to the minimum SF volume ratio. These ratios correspond to concrete transverse (Poisson's) tensile strains, but they do not always ensure the section's required ductility. The real value of an SF volume ratio is a function of the required ductility, which, in turn, is a design parameter. Besides, the maximum additional plastic deformations in beams, contributed by fibers, cannot exceed those in beams without fibers. Based on these requirements, a linear approximation of the "SF volume ratio - required ductility" function is proposed [10]. It allows calculation of the SF volume ratio for a required section's ductility.

\section{Calculation of SF volume ratio as a function of required section's ductility}

As in usual RC elements, after the minimum SF volume ratio is obtained, it is necessary to calculate the design one. The main principals for this design are: 
- by analyzing results of experimental investigations [1,11,12, 14-17], it can be concluded that SF in a bending pre-stressed section compressed zone adds plastic deformations, $\varepsilon_{\mathrm{c} f}$, after the $\varepsilon_{\mathrm{c} 2}$ value in a concrete matrix is achieved (see Fig. 4);

- the additional plastic deformations, $\varepsilon_{\mathrm{c}}$, should be calculated as a function of the required section ductility, $\mu_{\mathrm{req}}$, which is given as a design parameter;

- the total additional plastic deformations (taking into account the fiber confining effect) should be less then or equal to those without fibers [18]:

$$
\varepsilon_{\mathrm{cf}} \leq \varepsilon_{\mathrm{c} 2}
$$

The SF volume ratio is assumed to be a linear function of the required ductility.

Equation (6) limits the maximum value of the additional plastic deformations, $\varepsilon_{\mathrm{c} \text { f. }}$. It is important to also limit their minimum value. If cracks appear in the concrete matrix, fibers, added according to the min $\rho_{\mathrm{f}}$ value, can take the transverse tensile strains. In this case

$$
\min \varepsilon_{\mathrm{cf}}=\frac{\varepsilon_{c t u l}}{v}=\frac{1210^{-5}}{0.2}=0.610^{-3}
$$

where $v=0.2$ is the concrete Poisson's coefficient.

The additional ductility, contributed by SF, $\Delta \mu$, can be obtained as

$$
\Delta \mu=\mu_{\mathrm{req}}-\mu_{\mathrm{HSC}}
$$

where

$$
\Delta \mu=\varepsilon_{c f} /\left(0.5 \varepsilon_{\text {cel ul }}\right)
$$

Considering the fibers' confining effect and according to Eq. (6), the maximum additional ductility is

$$
\max \Delta \mu=2 \varepsilon_{c 2} / \varepsilon_{\text {celul }}
$$

The maximum required ductility (see Figure 4 ) is

$$
\max \mu_{\mathrm{req}}=\max \Delta \mu+\mu_{\mathrm{HSC}}=\frac{2 \varepsilon_{c 2}}{\varepsilon_{c e l u l}}+\frac{U_{c t o t}}{U_{c e l}}
$$

A graph of the SF volume ratio, $\rho_{\mathrm{f}}$, vs. $\mu_{\text {req }}$ is shown in Figure 5.

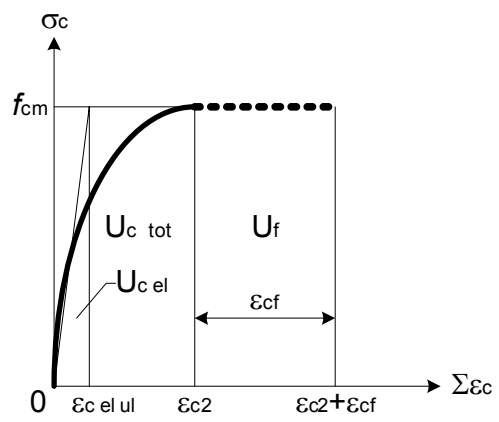

Figure 4: $\quad$ HSC and fibers plastic energy dissipation potentials $\left(U_{c}\right.$ tot and $\left.U_{f}\right)$. 


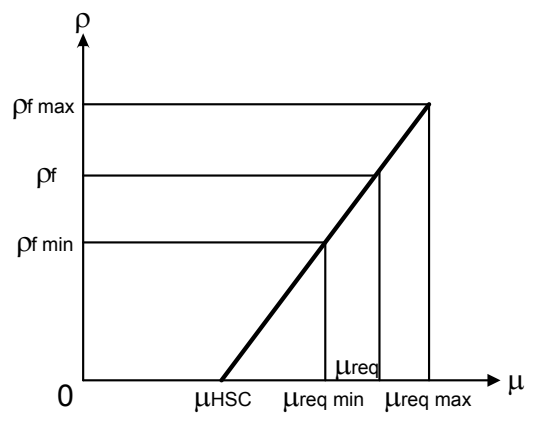

Figure 5: $\quad$ SF volume ratio, $\rho_{\mathrm{f}}$, vs. the required section ductility, $\mu_{\text {req }}$.

\section{Principles for definition of high performance RC bending elements}

Based on the above review of experimental and theoretical investigations, carried out by the authors and by other researchers, it is possible to formulate the following principles for defining HPBE:

- the properties of the element's material should be as close as possible to those of an elastic-ideal-plastic one;

- each section of an HPBE should be quasi-isotropic and the neutral axis should pass through its centre of gravity, i.e. the section's compressed zone depth is known;

- $\quad$ an HPBE should be made of two layers, allowing more effective use of the concrete strength and ductility in the section;

- $\quad$ concrete in the compressed zone should be fibered, according to a calculated SF ratio, in order to achieve the required ductility level;

- $\quad$ concrete in the tensile zone should be pre-stressed;

- the HPBE section's bearing capacity and its ductility cannot be increased more than twice, otherwise another material (different from traditional RC) will be created.

\section{Conclusions}

This paper deals with the problem of a strong definition of RC high performance bending elements (HPBE), and it is focused on the structural aspects only. Based on a definition of high strength concrete (HSC), previously given by the authors, a calculation method for fiber volume ratio was proposed. Following this definition, HSC is defined as the lowest concrete strength, satisfying the following requirements: absence of a download branch in the parabolic diagram of the concrete; minimum exponent of the $\sigma_{c}-\varepsilon_{c}$ function; and minimum ductility parameter of the concrete under compression.

Two-layer beams with HSC in the compression zone and normal strength concrete (NSC) in the tensile zone were studied, applying the above mentioned 
approaches. Such a beam is effective, if its section's compressed zone corresponds to a rather large bending moment. NSC, used in the section tensile zone, additionally contributes about $20 \%$ to the section's plastic energy dissipation, compared to one-layer HSC beams.

Using steel fibers (SF) significantly increases the ductility of the section. They have little effect on beams' elastic deflections, but increase the plastic energy dissipation potential of the section. It was proposed to add fibers only in the compression zone, where HSC is used. It avoids high fiber expenditure for a beam and increases the shear capacity of the section. The role of fibers for transverse tensile deformations absorption is similar to that of tensile reinforcement for longitudinal tensile stresses absorption in usual RC structures.

Based on the fact that SF takes the transverse (Poisson) tensile stresses, yielding cracks in the concrete matrix, a design method for calculation of the SF volume ratio, as a function of required ductility, was proposed. It forms a basis for a new design technique of HPBE.

Pre-stressing the tensile zone of the two-layer beam yields further improvement in its performance. A design method for such beams, consisting of steel fibered HSC in the compressed zone and pre-stressed NSC in the tensile zone was proposed. It follows that two-layer fibered HSC/NSC elements become high performance ones. Summarizing the above described methods, for the first time the main principles required for getting HPBE were formulated.

\section{References}

[1] Magnusson, J. and Hallgern, M. "Reinforced High Strength Concrete Beams Subjected to Air Blast Loading", Structures Under Shock and Impact VIII, Ed: Jones, N. and Brebbia, C.A., WIT Press, 2004.

[2] Eurocode 2: Design of Concrete Structures - Part 1-1: General Rules for Buildings, December 2004.

[3] Ramadan, O.M.O. and Kansouh, S.F. "An Empirical Model for Curvature Ductility of Reinforced High-Strength Concrete Sections", Proceedings of the Seventh International Conference on Computational Structures Technology, Lisbon, Paper No. 176, Civil-Comp Press, 2004.

[4] Pendyala, R., Mendis, P. and Patnaikuni, L. "Full Range Behavior of HighStrength RC Flexural Concrete Members", ACI Structural J., 93 (1), 1996.

[5] Mansur, M.A., Chain, M.S., and Wee, T.H. "Flexural Behavior of High Strength Concrete Beams", ACI Structural J., 94 (6), 1997.

[6] Shah S.A. and Ribakov Y. "Experimental and Analytical Study of FlatPlate Floor Confinement", Materials and Design, 26 (8), pp. 655-669, 2005.

[7] Iskhakov I. and Ribakov Y. "A design Method for Two-Layer Beams Consisting of Normal and Fibered High Strength Concrete", Materials and Design, 28, 1672-1677, 2007.

[8] Iskhakov I. "Influence of Concrete Pre-stressing and Gravitation Loading on Plastic Energy Dissipation and Ductility of RC Elements in Seismic Zones", Structures Under Shock and Impact VIII, Jones, N. and Brebbia, C.A. (Ed.), WIT Press, UK, 241-251, 2004. 
[9] Israel Standard IS 466, Part 1 "Concrete Code: General Principles", The Standards Institution of Israel, 2003.

[10] Iskhakov, I. and Ribakov, Y. "Two-layer pre-stressed beams consisting of normal and steel fibered high strength concrete", Materials and Design, available online from October 22, 2007.

[11] Savir, Z. and Dancygier, A.N. Structural behavior of high strength RC with steel fibers. In Zingoni A., editor. Progress in structural engineering, mechanics and computation. London: Tailor and Francis Group, 2004.

[12] Padmarajaiah, S.K. and Ramaswamy, A. Behavior of fiber-reinforced prestressed and reinforced high-strength concrete beams subjected to shear. ACI Structural Journal, 98 (5), September-October 2001, 752-760.

[13] Petitjean, J. and Resplendino, J. French recommendations for ultra-high performance fiber-reinforced concrete. In: Konig, G., Dehn, F. and Faust, T. High strength / high performance concrete, 1, Leipzig, 2002, 485-498.

[14] Lin, C.H. and Lee, F.S. Ductility of high performance concrete beams with high strength lateral reinforcement. ACI Structural J., 98 (4), 2001, 600 608.

[15] Narayanan, R. and Darwish, Y.I.S. Use of steel fibers as shear reinforcement. ACI Structural Journal 1987; May-June, 216-226.

[16] Dumet, T.B. and Pinheiro, L.M. Experimental investigation of the local bond stress-slip behavior of pre-tensioned strands embedded in plane and steel-fibered reinforced concrete. In: Konig, G., Dehn, F. and Faust, T. High strength / high performance concrete, 1, Leipzig, 2002, 221-234.

[17] Lapko, A. and Sadowska-Buraczewska, B. Carrying capacity and deformability of hybrid beams made of HSC and normal concrete. In: Konig, G., Dehn, F. and Faust, T. High strength / high performance concrete, 1, Leipzig, June 2002, 137-148.

[18] Iskhakov, I. "Quasi-Isotropic Ideally Elastic-Plastic Model for Calculation of RC Elements without Empirical Coefficients", in Structural Engineering, Mechanics and Computation, 1, Ed. Zingoni, A., Elsevier Science Ltd., Oxford, 2001.

[19] Xue, W., Li, L., Cheng, B. and Li, J. "The reversed cyclic load tests of usual and pre-stressed concrete beams". Engineering Structures (available online from August 9, 2007). 